\title{
Effects of twin pregnancy chorionic properties on fetal outcomes: a comparative study
}

\author{
Gigi A.*, Rachel Alexander, Radhamani K.
}

Department of Obstetrics and Gynecology, T. D. Medical College, Vandanam, Alappuzha, Kerala, India

Received: 11 July 2020

Accepted: 07 August 2020

\section{*Correspondence:}

Dr. Gigi A.,

E-mail: gigiantony100@gmail.com

Copyright: (C) the author(s), publisher and licensee Medip Academy. This is an open-access article distributed under the terms of the Creative Commons Attribution Non-Commercial License, which permits unrestricted non-commercial use, distribution, and reproduction in any medium, provided the original work is properly cited.

\begin{abstract}
Background: Twins carry significant risks to both mothers and babies. The purpose of this study was to evaluate chorionicity and its impact on perinatal outcomes in twins.

Methods: This prospective observational study was conducted in the department of obstetrics and gynecology, Government T. D. Medical College, Alappuzha, Kerala. A total of 106 cases of twin pregnancies were included in the prospective descriptive study. Based on the ultrasound results and methods of the postpartum pathologic examination of the placental membranes, the cases were divided into the twin group with monochorionic diamniotic (MCDA) and twin group with dichorionic diamniotic (DCDA group). The relationships of different chorionic properties and fetal outcomes were determined by comparing various fetal outcomes.

Results: Among 106 twin pregnancies, 61.3\% were DCDA twins, 38.7\% were MCDA. Average maternal age of monochorionic twin was 25 and that of dichorionic twin was 27. Perinatal mortality of monochorionic twin was $14.7 \%$ when compared to $8.6 \%$ for dichorionic twin. The mean gestational age for monochorionic twin pregnancy was 34.78 weeks whereas it was 35.91 weeks for dichorionic pregnancy. Elective and emergency LSCS was done more for dichorionic twin pregnancies compared to monochorionic twin pregnancies. Low Apgar scores were seen in monochorionic twins compared to dichorionic twins.

Conclusions: The incidence of fetal outcomes in the monochorionic group was inferior to those in the dichorionic group. The fetal outcomes may be improved by determining the chorionic properties in early pregnancy by using ultrasound and consequently planning for pregnancy monitoring and intervention.
\end{abstract}

Keywords: Apgar scores, Dichorionic, Monochorionic, Perinatal outcome

\section{INTRODUCTION}

One of the most fascinating events occurring in human reproductive biology is multiple pregnancies. During the recent decades, multiple pregnancy and multiple livebirth rates have increased. This may be due to postponement of maternity on the part of women and the dissemination of assisted reproduction techniques. ${ }^{1}$ Worldwide the multiple pregnancy accounts for $3 \%$ of all the pregnancies and the rate of twin birth has increased by more than $75 \%$ in the United States from 1980 to 2009..$^{2-4}$ Similar trends have been observed in Western Europe and other countries. ${ }^{5}$ In India, twins account for
$1 \%$ of all pregnancies, but contribute to $10 \%$ of perinatal mortality, $12.2 \%$ of preterm births and $15.4 \%$ of neonatal deaths. ${ }^{6-9}$

Dizygotic and monozygotic twins are the two types of twins. Dizygotic twins result from the fertilisation of two different eggs, by two spermatozoa with an incidence of 7 to 11 per 1000 births. The second type of twins is monozygotic, which results from the splitting of the zygote at various stages of development with an incidence of 3 to 4 per 1000 births. ${ }^{10}$ Monozygotic twins may be dichorionic diamniotic, monochorionic diamniotic, monochorionic monoamniotic and even 
conjoined, depending on the time between fertilization and cleavage. In $30 \%$ of monozygotic twins, cleavage occurs by the third day of fertilization resulting in dichorionic diamniotic pregnancy. ${ }^{11}$ Monochorionic twin gestations are at increased risk of a variety of pregnancy complications which can be minimized by early antepartum diagnosis and management. This study endeavours to evaluate the influence of chorionicity in twin pregnancies on perinatal outcome.

Twin pregnancy poses definite risks not only to the mother but also to the fetuses. Woman pregnant with twins are nearly six times more likely to be hospitalized during pregnancy, with complications such as preterm labour, gestational hypertension, preterm premature rupture of the membranes and more likely to be admitted to ICU. Maternal length of stay during the birth admission is 60 to $70 \%$ higher for multiple versus singleton births. Despite advances in the obstetrics and neonatology the perinatal mortality among twins still remains high. The higher preterm delivery rate in twins, either from spontaneous or induced labour with its associated problems of prematurity remains the major cause of morbidity and mortality. Other factors which contribute to higher perinatal mortality include fetal growth retardation, discordant growth and twin to twin transfusion syndrome. Mortality rates for twins are increased to 5 to 7 folds compared with singletons. Twin pregnancies produce children with cerebral palsy 12 times more often than do singleton pregnancies. However, at a closer look it is chorionicity that determines the fetal outcome. Studies have also revealed difference in perinatal mortality rate in relation to chorionicity. This study aims to assess the morbidity and mortality of fetuses in relation to chorionicity.

\section{Objectives}

- To find out the incidence of monochorionic and dichorionic twin pregnancies in the department of obstetrics and gynecology, Government TD Medical College, Alappuzha.

- To study the influence of the chorionicity on perinatal outcome.

\section{METHODS}

This study was an observation study conducted at the department of obstetrics and gynecology, Government TD Medical College, Alappuzha. The study protocol was approved by the Regional Committee for Medical Research Ethics. The period of study was for 18 months. 106 cases of twin pregnancies beyond 24 weeks of gestation admitted in the hospital were taken as the study group. A detailed history was taken; clinical examination and analysis of investigation including ultrasound were done. All the participants were informed about this research and written consents were obtained from each participant.
Patients were followed up from antenatal period after admission to antenatal ward and labour room. Pregnancies were classified as monochorionic and dichorionic twin pregnancies according to ultrasonographic criteria and postpartum histological assessment of the placenta. Once the first twin is delivered, per abdominal and vaginal examination were repeated and delivery of second twin was facilitated. Blood was arranged in all cases and active management of third stage was practiced. The chorionicity of placenta was confirmed after the delivery of both the babies. The perinatal outcomes of babies were analysed based on birth weight, Apgar scores at birth, NICU admission and the factors like number of macerated births, still birth NND's etc. Perinatal mortality was calculated using the following formula;

$$
\text { Perinatal mortality }=\frac{\begin{array}{c}
\text { Total number of late foetal death and early } \\
\text { neonatal death having birth weight }>1000 \mathrm{~g}
\end{array}}{\text { Total no. }: \text { of live births }} \times 1000
$$

\section{Statistical analysis}

The descriptive statistics of the study population was calculated. Statistical analyses such as chi-square test and paired t-test were carried. Statistical analysis was performed using the software SPSS.

\section{RESULTS}

Total number of deliveries during the study period was 8125 , of which 121 were twins' pregnancies. The incidence of twin pregnancy was $1.5 \%$ during the study period. The sample size for this study was 106 twin deliveries. Out of 106 twin deliveries, the incidences of monochorionic and dichorionic twins were $38.7 \%$ and $61.3 \%$ respectively (Figure 1 ).

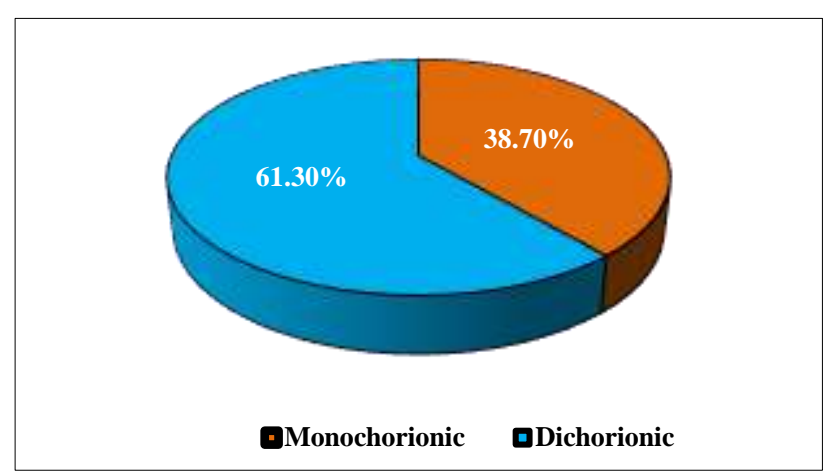

Figure 1: Distribution of monochorionic and dichorionic pregnancies.

Table 1 depicts the distribution of maternal age in monochorionic and dichorionic twins' pregnancies. The mean maternal age for monochorionic pregnancy was 25 years and for dichorionic pregnancy was 27 years. The $\mathrm{P}$ value was 0.046 , therefore it can be concluded that there was statistically significant difference between the maternal ages of Group I and Group II. 
Table 1: Distribution according to maternal age.

\begin{tabular}{|lllll|}
\hline Maternal age in & \multicolumn{2}{c|}{ Monochorionic } & \multicolumn{2}{l|}{ Dichorionic } \\
years & No. & \% & No. & \% \\
\hline$<\mathbf{2 0}$ & 1 & 2.4 & 2 & 3.1 \\
\hline $\mathbf{2 0 - 2 4}$ & 22 & 53.7 & 26 & 40 \\
\hline $\mathbf{2 5 - 2 9}$ & 12 & 29.3 & 27 & 41.5 \\
\hline$>\mathbf{3 0}$ & 6 & 14.6 & 10 & 15.4 \\
\hline Total & 41 & 100 & 65 & 100 \\
\hline
\end{tabular}

Table 2: Distribution according to gravidity.

\begin{tabular}{|lll|}
\hline Gravidity & Monochorionic (\%) & Dichorionic (\%) \\
\hline Primi & 56.1 & 46.2 \\
\hline G2 & 34.1 & 40 \\
\hline G3 & 7.3 & 13.8 \\
\hline G4 & 2.4 & 0.0 \\
\hline
\end{tabular}

Distribution of pregnant women according to gravidity is presented in Table 2. In monochorionic and dichorionic twin pregnancies, primi gravidas contributed the largest percentage. In this study, there were $2.4 \%$ of fourth gravidas in monochorionic group when compared to none in the dichorionic group.

Table 3: Distribution of according to parity.

\begin{tabular}{|lllll|}
\hline \multirow{2}{*}{ Parity } & \multicolumn{2}{c}{ Monochorionic } & \multicolumn{2}{c|}{ Dichorionic } \\
\hline Nullipara & No. & $\mathbf{\%}$ & No. & \% \\
\hline Primipara & 15 & 58.5 & 34 & 52.3 \\
\hline Multipara & 2 & 36.6 & 27 & 41.5 \\
\hline Total & 41 & 4.9 & 4 & 6.2 \\
\hline
\end{tabular}

Table 4: Distribution according to gestational age at the time of delivery.

\begin{tabular}{|lll|}
\hline $\begin{array}{l}\text { Gestational } \\
\text { age (weeks) }\end{array}$ & Monochorionic (\%) & Dichorionic (\%) \\
\hline $\mathbf{2 8}$ & 7.3 & 0.0 \\
\hline $\mathbf{2 8 - 3 1}$ & 4.9 & 7.7 \\
\hline $\mathbf{3 2 - 3 4}$ & 22 & 13.8 \\
\hline $\mathbf{3 5 - 3 7}$ & 53.7 & 55.3 \\
\hline $\mathbf{3 8 - 4 0}$ & 12.2 & 23.2 \\
\hline
\end{tabular}

Table 3 shows the distribution of parity. Nullipara contributed the largest group in both monochorionic and dichorionic pregnancies. There was no grand multipara in either of the study groups

Table 4 depicts the distribution according to gestational age at the time of delivery in monochorionic and dichorionic pregnancies. The average gestational age in monochorionic group was 35 weeks with a standard deviation of 0.51 and in dichorionic group it was 36 weeks with a standard deviation of 0.29 . The $p$ value was 0.058 and hence there was no significant difference in gestational age between two groups.
Table 5: Distribution according to presentation of fetus.

\begin{tabular}{|lllll|}
\hline \multirow{2}{*}{ Presentation } & \multicolumn{2}{l}{ Monochorionic } & \multicolumn{2}{l|}{ Dichorionic } \\
\hline Vertex-vertex & 23 & $\mathbf{\%}$ & No. & \% \\
\hline Vertex-breech & 6 & 14.6 & 13 & 43.1 \\
\hline Vertex-transverse & 1 & 2.4 & 0 & 0 \\
\hline Breech-breech & 5 & 12.2 & 11 & 16.9 \\
\hline Breech-vertex & 5 & 12.2 & 11 & 16.9 \\
\hline Breech-transverse & 1 & 2.4 & 1 & 1.5 \\
\hline $\begin{array}{l}\text { Transverse- } \\
\text { transverse }\end{array}$ & 0 & 0.0 & 1 & 1.5 \\
\hline Total & 41 & 100 & 65 & 100 \\
\hline
\end{tabular}

The distribution according to the presentation of fetus is presented in Table 5. The frequency of presentation was also comparable for both monochorionic and dichorionic types. The common presentation frequency amongst both twins was that of vertex- vertex. Incidence of $1^{\text {st }}$ baby in non-vertex presentation in monochorionic twins was $26.8 \%$ and that of dichorionic twins was $36.9 \%$, contributing a major indication for caesarean section.

The distribution of mode of delivery in monochorionic and dichorionic groups is depicted in Table 6. The incidence of vaginal delivery was found to be highest in monochorionic twins. LCSC percentage was higher in dichorionic twins.

Figure 2 shows the distribution according to type of placenta. Monochorionic monoamniotic (MCMA) placenta was found in least percentage. Dichorionic diamniotic (DCDA) placenta was found highest percentage followed by monochorionic diamniotic (MCDA). Out of the two MCMA twins, one was detected at 9th week and was followed up with more frequent antenatal visits, ultrasound and doppler studies. Patient presented with PROM at 35 weeks and emergency LSCS was done delivering babies weighing $2.1 \mathrm{~kg}$ and $1.75 \mathrm{~kg}$. Second case of MCMA twin was referred from local hospital at 35 weeks with oligoamines and PIH. At $22^{\text {nd }}$ week patient had done USG which showed Monochorionic diamniotic placentation. First baby was vertex presentation. Labour was induced and the patient delivered the first twin without any complication. Cord of the $1^{\text {st }}$ and $2^{\text {nd }}$ twin was entangled and there was no separating membrane. $2^{\text {nd }}$ baby was delivered by assisted breech delivery. Placenta was examined thoroughly and monochorionic monoamniotic status of placenta was confirmed.

Distribution of birth weights of monochorionic twins (first fetus and second fetus) is depicted in Table 7. In monochorionic group was the average birth weight of first fetus (F1) was $1.9 \mathrm{~kg}$ with a standard deviation of $0.56 \mathrm{~kg}$ and the average birth weight of second fetus (F2) was $1.7 \mathrm{~kg}$ with standard deviation of $0.62 \mathrm{~kg}$. The $\mathrm{p}$ value was 0.008 and it indicates that there was significant 
different between the birth weight of two fetus within monochorionic twins.

Table 8 portrays the birth weights of dichorionic twins. In dichorionic group the average birth rate of first fetus (F1) was $2.1 \mathrm{~kg}$ and the standard deviation was $0.41 \mathrm{~kg}$. The average birth weight of second fetus (F2) was $2.07 \mathrm{~kg}$ with standard deviation of $0.45 \mathrm{~kg}$. The $\mathrm{p}$ value $(0.225)$ indicates that there was no significant difference between the birth weights of two fetuses within dichorionic twins. None of the fetus had a birth weight more than $3 \mathrm{~kg}$.
Table 9 shows the discordancy in birth weights in monochorionic and dichorionic twins. $22 \%$ of incidence of more than $25 \%$ discordancy was found in monochorionic babies compared to $9.2 \%$ in dichorionic babies. In monochorionic group the average discordancy was $17 \%$ with a standard deviation of 13 . Whereas in dichorionic twins the average discordancy was $10.88 \%$ with a standard deviation of 9.08. Authors also found significant difference between the discordancy of monochorionic and dichorionic twins ( $\mathrm{p}$ value is 0.010 ).

Table 6: Distribution according to mode of delivery.

\begin{tabular}{|lllll|l|}
\hline \multirow{2}{*}{ Mode of delivery } & Mode of delivery (sub classifications) & \multicolumn{3}{l|}{ Monochorionic } & Dichorionic \\
\hline \multirow{2}{*}{ Vaginal } & Vaginal delivery & No. & \% & No. & \% \\
\hline \multirow{2}{*}{ Abdominal } & Vaginal delivery $-\mathrm{I}^{\text {st }}$ Vx assisted breech & 21 & 51.2 & 21 & 32.3 \\
\hline Combined vaginal abdominal & Emective LSCS & 2 & 7.3 & 3 & 4.6 \\
\hline & Emency LSCS & 15 & 4.9 & 11 & 16.9 \\
\hline Total & & 0 & 0 & 1 & 1.5 \\
\hline
\end{tabular}

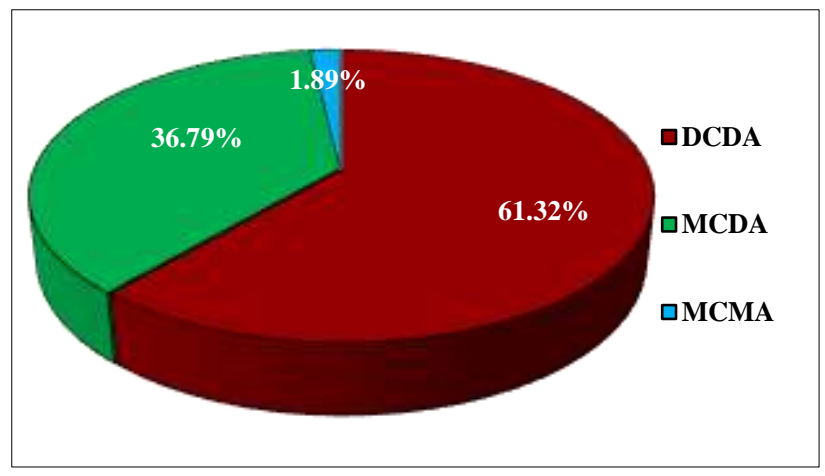

Figure 2: Distribution according to type of placenta.

Table 7: Distribution of birth weights of monochorionic twins.

\begin{tabular}{|lllll|}
\hline \multirow{2}{*}{ Birth weight $(\mathrm{kg})$} & $\begin{array}{l}\text { First fetus } \\
\left(\mathrm{F}_{\mathbf{1}}\right)\end{array}$ & $\begin{array}{l}\text { Second fetus } \\
\left(\mathrm{F}_{2}\right)\end{array}$ \\
\cline { 2 - 5 } & No. & \% & No. & \% \\
\hline$<\mathbf{1}$ & 3 & 7.3 & 6 & 14.6 \\
\hline $\mathbf{1 - 1 . 5}$ & 9 & 22.0 & 9 & 22.6 \\
\hline $\mathbf{1 . 6 - 2}$ & 12 & 29.3 & 14 & 34.1 \\
\hline $\mathbf{2 . 1 - 2 . 5}$ & 13 & 31.7 & 9 & 2.0 \\
\hline $\mathbf{2 . 6 - 3}$ & 3 & 7.3 & 2 & 4.9 \\
\hline $\mathbf{3 . 1 - 3 . 6}$ & 1 & 2.4 & 1 & 2.4 \\
\hline Total & 41 & 100 & 41 & 100 \\
\hline
\end{tabular}

Table 10 shows the distribution of fetal growth restriction (FGR). Monochorionic babies were having much higher incidence of FGR. $76.8 \%$ of monochorionic twins showed FGR and $60 \%$ of dichorionic twins showed FGR.
Table 8: Distribution of birth weights of dichorionic twins.

\begin{tabular}{|lllll|}
\hline \multirow{2}{*}{$\begin{array}{l}\text { Birth weight } \\
\text { (kg) }\end{array}$} & \multicolumn{2}{l}{ First fetus (F1) } & \multicolumn{2}{l|}{ Second fetus (F2) } \\
\hline$<\mathbf{1}$ & 0 & 0 & 2 & 3.1 \\
\hline $\mathbf{1 - 1 . 5}$ & 10 & 15.4 & 9 & 13.8 \\
\hline $\mathbf{1 . 6 - 2}$ & 15 & 23.1 & 21 & 32.3 \\
\hline $\mathbf{2 . 1 - 2 . 5}$ & 34 & 52.3 & 24 & 36.9 \\
\hline $\mathbf{2 . 6 - 3}$ & 6 & 9.2 & 9 & 13.8 \\
\hline $\mathbf{3 . 1 - 3 . 6}$ & 0 & 0 & 0 & 0 \\
\hline Total & 65 & 100 & 65 & 100 \\
\hline
\end{tabular}

Table 9: Distribution of discordancy.

\begin{tabular}{|lllll|}
\hline \multirow{2}{*}{ Discordancy } & \multicolumn{2}{l|}{ Monochorionic } & \multicolumn{2}{l|}{ Dichorionic } \\
\cline { 2 - 5 } & No. & \% & No. & \% \\
\hline$<\mathbf{1 5}$ & 23 & 56.1 & 47 & 72.3 \\
\hline $\mathbf{1 5 - 2 4}$ & 9 & 22 & 12 & 18.5 \\
\hline$>\mathbf{2 5}$ & 9 & 22 & 6 & 9.2 \\
\hline Total & 41 & 100 & 65 & 100 \\
\hline
\end{tabular}

Apgar scores of all new born babies were noted at one minute and after five minutes of birth. The summary of Apgar scores of monochorionic and dichorionic twins at one minute and five minutes are presented in Table 11. Percentage of dichorionic twins (fetus 1 and fetus 2) with an Apgar score less than 4 was nil. More than $90 \%$ of babies (F1 and F2) born in dichorionic group had a higher Apgar score greater than 7. The mean Apgar score of $\mathrm{F} 1$ in monochorionic twins at 1 minute was 7.9 with a standard deviation of 2.9. Whereas the mean 
Table 10: Distribution of fetal growth restrictions (FGR) in relation to chorionicity.

\begin{tabular}{|lllll|}
\hline \multirow{2}{*}{ FGR } & \multicolumn{2}{c|}{ Monochorionic } & \multicolumn{2}{c|}{ Dichorionic } \\
& No. & \% & No. & \% \\
\hline Present & 63 & 76.8 & 79 & 69 \\
\hline Absent & 19 & 23.2 & 51 & 40 \\
\hline Total & 82 & 100 & 130 & 100 \\
\hline
\end{tabular}

Apgar score of F1 in dichorionic twins was 8.9 with a standard deviation of 1.28. There was no significant difference $(p$ value $=0.118)$ between the $F 1$ fetus in monochorionic and dichorionic twins. The mean Apgar score of F2 in monochorionic twins at one minute was 6.78 with a standard deviation of 3.6. Whereas the mean Apgar score of F2 in dichorionic twins was 8.25 with a standard deviation of 1.37. As the $\mathrm{p}$ value was 0.007 , authors found significant difference between the F2 fetus in monochorionic and dichorionic twins.

The mean Apgar score of F1 in monochorionic twins at 5 minutes was 7.61 with a standard deviation of 2.75. Whereas the mean Apgar score of F1 in dichorionic twins was 8.6 with a standard deviation of 1.51 . There was significant difference ( $\mathrm{p}$ value $=0.037)$ between the $\mathrm{F} 1$ fetus in monochorionic and dichorionic twins. The mean Apgar score of F2 in monochorionic twins at five minutes was 6.63 with a standard deviation of 3.5. Whereas the mean Apgar score of F2 in dichorionic twins was 8.38 with a standard deviation of 1.61. Authors found significant difference between the F2 fetus in monochorionic and dichorionic twins ( $p$ value 0.004 ).

Table 11: Apgar scores of first and second fetus.

\begin{tabular}{|c|c|c|c|c|c|c|c|c|c|}
\hline \multirow{3}{*}{ Apgar score } & & \multicolumn{4}{|c|}{ Monochorionic fetus } & \multicolumn{4}{|c|}{ Dichorionic fetus } \\
\hline & & \multirow{2}{*}{$\begin{array}{l}\text { F1 } \\
\text { No. }\end{array}$} & & \multicolumn{2}{|l|}{$\mathbf{F}_{2}$} & \multicolumn{2}{|c|}{$F_{1}$} & \multicolumn{2}{|l|}{$F_{2}$} \\
\hline & & & $\%$ & No. & $\%$ & No. & $\%$ & No. & $\%$ \\
\hline \multirow{3}{*}{$\begin{array}{l}\text { Apgar score } \\
\text { at } 1 \text { minute }\end{array}$} & $<4$ & 4 & 9.8 & 9 & 22 & 1 & 1.5 & 0 & 0 \\
\hline & $4-7$ & 3 & 7.3 & 4 & 9.8 & 2 & 3.1 & 6 & 9.2 \\
\hline & $>7$ & 34 & 82.9 & 28 & 68.3 & 62 & 95.4 & 59 & 90.8 \\
\hline \multirow{3}{*}{$\begin{array}{l}\text { Apgar score } \\
\text { at } 5 \text { minutes }\end{array}$} & $<4$ & 5 & 12.2 & 9 & 22 & 5 & 12.2 & 9 & 22 \\
\hline & $4-7$ & 3 & 7.3 & 4 & 9.8 & 3 & 7.3 & 4 & 9.8 \\
\hline & $>7$ & 33 & 80.5 & 28 & 68.3 & 33 & 80.5 & 28 & 68.2 \\
\hline
\end{tabular}

Table 12: Distribution of babies according to NICU admission and perinatal mortality.

\begin{tabular}{|llllll|}
\hline & & \multicolumn{2}{c}{ Monochorionic } & \multicolumn{2}{c|}{ Dichorionic } \\
\cline { 3 - 6 } Admission to NICU & No. & $\mathbf{\%}$ & No. & \% \\
\cline { 3 - 6 } & Admitted & 49 & 59.7 & 58 & 44 \\
\cline { 2 - 6 } Fetal outcome & Not admitted & 52 & 64 & 72 & 56 \\
\cline { 2 - 6 } & Total live babies & 63 & 76.83 & 117 & 90 \\
\cline { 2 - 6 } & Total perinatal death & 19 & 23.17 & 13 & 9.9 \\
\hline
\end{tabular}

Table 13: Distribution of congenital anomalies in fetus.

\begin{tabular}{|lll|}
\hline Type of congenital anomalies & No. & Chorionicity \\
\hline Congenital heart disease & 1 & MCDA \\
\hline $\begin{array}{l}\text { Pelvis calyces dilation of the } \\
\text { kidney }\end{array}$ & 1 & MCDA \\
\hline Diaphragmatic hernia & 1 & DCDA \\
\hline Hydro cephalous & 1 & DCDA \\
\hline CTEV & 1 & DCDA \\
\hline Hypospadias & 1 & DCDA \\
\hline Hypothyroidism & 1 & DCDA \\
\hline Total & 8 & \\
\hline
\end{tabular}

Distribution of babies according to NICU admission and perinatal mortality rate are depicted in Table 12 . Out of the total 49 monochorionic twins admitted to NICU, 20 were first fetus babies and remaining 29 were second fetus babies. In dichorionic twins, 27 first fetus and 31 second fetus were admitted in NICU. The indications for the admission into NICU were due to prematurity, prematurity with FGR, birth asphysia, sepsis, hyperbilirubinemia, NEC. The perinatal mortality rate of monochorionic and dichorionic twins were $14.7 \%$ and $8.6 \%$ respectively. Authors also calculated the perinatal mortality rate of first and second fetus in both monochorionic and dichorionic twins.

Perinatal mortality rate of first fetus was $7.9 \%$ and it was $21.2 \%$ for second fetus in monochorionic twins. Whereas the perinatal mortality rate of first and second fetuses in dichorionic twin were $10.7 \%$ and $6.3 \%$ respectively. Out of the 19 perinatal deaths of monochorionic twins there 
were four freshes still births (FSB), 7 macerated birth and 8 neonatal deaths (NND). In the 8 neonatal deaths, there were 3 first fetus and 5 second fetus in monochorionic twins. The causes of neonatal death in monochorionic twins were prematurity, prematurity with FGR and birth asphyxia. In dichorionic twins, a total of 12 neonatal deaths and 1 macerated birth were reported. The reasons for the neonatal death in dichorionic twins were due to prematurity, prematurity with FGR, birth asphyxia and diaphragmatic hernia. In monochorionic twin pregnancies there was 5 cases of single fetal demise and in dichorionic twin pregnancies only one case of fetal demise was reported. Table 13 shows the distribution of congenital anomalies in fetus. Incidence of congenital anomaly in monochorionic twin was $2.6 \%$ whereas it was $3.8 \%$ in dichorionic twins.

\section{DISCUSSION}

Twin pregnancy opens a fertile field for discussion and study of all obstetric complications that can occur in single patients. This clinical study to evaluate perinatal outcome in twin pregnancies was conducted at TDMC Alappuzha for 18 months. The incidences of monochorionic and dichorionic twins were $38.7 \%$ and $61.3 \%$ respectively. The studies of Ruhle et al $(33 \%$ monochorionic twins and $67 \%$ dichorionic twins), Hatkar et al $(29 \%$ monochorionic twins and $71 \%$ dichorionic twins), Mahmut et al (30.7\% monochorionic twins and $69.3 \%$ dichorionic twins) also showed a higher incidence of dichorionic twins. ${ }^{12-14}$

Maximum incidence of monochorionic twin pregnancy was in the age group of 20 to 24 years. In dichorionic twins, higher incidence was in the age group of 25 to 29 years. The higher mean age of women in the dichorionic twin pregnancy may be due to prolonged period of infertility and treatment with ovulation induction. Monochorionic twins had higher incidence in primis than in dichorionic twins. There was only one $4^{\text {th }}$ gravida in the entire study group. Increased incidence in primi gravida may be because they account for the largest group in the study is probably due to infertility treatment. Nullipara contributed the largest group in both monochorionic and dichorionic pregnancies. There was no grand multipara in the study group. Reason for this may due to implementation of effective family planning methods.

Preterm labor is the one major complication on which zygosity has an influence. ${ }^{15}$ This study also supports this. The average gestational age of monochorionic twin pregnancies is 34.8 weeks and dichorionic is 35.9 weeks. ${ }^{16}$ Increased occurrence of preterm babies in monochorionic twin population may due to higher incidence of preterm premature rupture of membranes, polyhydramnios etc. ${ }^{17}$ Higher incidence of caesarean section in dichorionic twins was due to high ratio of nonvertex presentation of $1^{\text {st }}$ twin $(36.9 \%)$ and also due to higher incidence of previous caesarean section cases.
Commonest indication for caesarean section in monochorionic twin pregnancy was non vertex presentation of $1^{\text {st }}$ baby. In monochorionic twin pregnancies 3 vertex-breech presentation had vaginal delivery for the $1^{\text {st }}$ twin and assisted breech delivery for the $2^{\text {nd }}$ twin without any complication. In dichorionic twin pregnancies, 3 out of 13 vertex breech presentations had vaginal delivery for the $1^{\text {st }}$ twin and assisted breech delivery for the $2^{\text {nd }}$ twin.

Discordancy in birth weight can be classified into two grades. Grade 1 consists of discordancy in birth weight $>15 \%$ and $>15$ to $<25 \%$, whereas Grade 2 consists of discordancy in birth weight $>25 \%$. Monochorionic twin babies showed higher incidence of Grade 2 disparity in birth weight than dichorionic twin babies. The high incidence of discordant growth in monochorionic twins may be due to twin to twin transfusion. Fetal growth restriction was higher in monochorionic twins. Literature also shows higher incidence of FGR in monochorionic twins compared to dichorionic twins. Nearly $50 \%$ of babies were admitted in NICU in both groups. $2^{\text {nd }}$ fetus of the twin had slightly higher incidence of NICU admission. Prematurity was the commonest cause for NICU admission. This may be also due to electively induced preterm birth for fetal factors like FGR, oligoamnios and single fetal death of one baby. Prematurity was also associated with its complications like HMD, NEC, hypoglycaemia. FGR was 2nd most common indication.

Perinatal mortality is considered as the best indicator of obstetric care received by the patient. In this study, the total number of total fetuses was 212 (82 monochorionic and 130 dichorionic). In monochorionic twins there were a total of 19 perinatal deaths which consisted of 7 macerated deaths, 8 NND and 4 FSB and in dichorionic twins' total number of perinatal deaths were 13 of which one macerated death and twelve NND. Many studies also showed high perinatal mortality rates in monochorionic twins. In the study of Potter et al the perinatal mortality rate of monochorionic twins was $13.2 \%$ and dichorionic twins was $9.6 \% .^{18}$ There were two babies with major fatal congenital anomalies in the form of diaphragmatic hernia and hydrocephalous. Both were first babies of dichorionic twins. This may be the cause of high perinatal mortality in first baby of dichorionic twin. The most common cause for neonatal death was prematurity followed by severe FGR.

\section{CONCLUSION}

Twin pregnancies are at greater risk for growth abnormalities and other complications. Authors studied the influence of chorionicity on pregnancy and perinatal outcome in twins. Most of the factors identified in this study were found to be consistent with known risk factors in various other studies. Total number of deliveries during the study period was 8125 , of which 121 were twins' deliveries. This study consisted of sample size 
106. Among 106 twin pregnancies, $61.3 \%$ were dichorionic diamniotic twins, $38.7 \%$ were monochorionic diamniotic. Average maternal age of monochorionic twin was 25 and that of dichorionic twin was 27 . Perinatal mortality of monochorionic twin was $14.7 \%$ when compared to $8.6 \%$ for dichorionic twin. Higher incidence of fetal demise was found in monochorionic twin pregnancy. The mean gestational age for monochorionic twin pregnancy was 34.8 weeks whereas it was 35.9 weeks for dichorionic pregnancy. Elective and emergency LSCS was done more for dichorionic twin pregnancies compared to monochorionic twin pregnancies. The mean birth weight of monochorionic twins was $1.77 \mathrm{~kg}$ compared to $2.09 \mathrm{~kg}$ among dichorionic twins. Low Apgar scores were seen in monochorionic twins compared to dichorionic twins.

Monochorionicity was significantly associated with pregnancy complications and adverse perinatal outcome. Perinatal morbidity due to chorionicity can be reduced with modern management, timely diagnosis and intervention. Hence early diagnosis of chorionicity and referral to a tertiary centre with fetal medicine unit and new born care is very important in reducing morbidity and perinatal mortality among MC twins. Importance of antenatal care should be conveyed to the pregnant mother by educating them about the risks and complications of chorionicity.

Funding: No funding sources

Conflict of interest: None declared

Ethical approval: The study was approved by the Institutional Ethics Committee

\section{REFERENCES}

1. Assunção RA, Liao AW, Brizot MDL, Krebs VLJ, Zugaib M. Perinatal outcome of twin pregnancies delivered in a teaching hospital. Rev Assoc Méd Bras. 2010;56:447-51.

2. Pharoah PO, Glinianaia SV, Rankin J. Congenital anomalies in multiple births after early loss of a conceptus. Hum Reprod. 2009;24:726-31.

3. Martin JA, Hamilton BE, Osterman MJ. Three decades of twin births in the United States, 19802009. NCHS Data Brief; 2012:1-8.

4. Collins J. Global epidemiology of multiple birth. Reprod Biomed Online. 2007;15(Suppl 3):45-52.

5. Pison G, D'Addato AV. Frequency of twin births in developed countries. Twin Res Hum Genet. 2006;9:250-9.
6. Blondel B, Kaminski M. Trends in the occurrence, determinants, and consequences of multiple births. In Seminars in perinatology. WB Saunders. 2002;;26(4):239-49.

7. Norwitz ER, Edusa V, Park JS. Maternal physiology and complications of multiple pregnancy. In Seminars in perinatology. WB Saunders. 2005;29(5):338-48.

8. Ghai V, Vidyasagar D. Morbidity and mortality factors in twins. An epidemiologic approach. Clin Perinatol. 1988;15(1):123-40.

9. Gardner MO, Goldenberg RL, Cliver SP, Tucker JM, Nelson KG, Copper RL. The origin and outcome of preterm twin pregnancies. Obstet Gynecol. 1995;85(4):553-7.

10. Sadler TW. Longman medical embryology, $10^{\text {th }}$ edition; 2006:104-8.

11. Al Riyami N, Al-Rusheidi A, Al-Khabori M. Perinatal outcome of monochorionic in comparison to dichorionic twin pregnancies. Oman Med J. 2013;28(3):173-7.

12. Guaschino S, Spinillo A, Stola E, Pesando PC. Growth retardation, size at birth and perinatal mortality in twin pregnancy. Int J Gynaecol Obstet. 1987;25:399-403.

13. Hatkar PA, Bhide AG. Perinatal outcome of twins in relation to chorionicity. J Postgrad Med. 1999;45:3384.

14. Erdemoğlu M, Kale A, Akdeniz N, Yalınkaya A, Özcan Y, Yayla M. Retrospective analysis of multiple pregnancies. Turkish J Perinatol. 2005;13:213-7.

15. Smits J, Monden C. Twinning across the developing world. PLoS One. 2011;6(9):e25239.

16. Hatkar PA, Bhide AG. Perinatal outcome of twins in relation to chorionicity. J Postgraduate Med. 1999;45(2):33.

17. Cheung YB, Yip P, Karlberg J. Mortality of twins and singletons by gestational age: a varying coefficient approach. Am J Epidemiol. 2000;152(12):1107-16.

18. Bronsteen R, Goyert G, Bottoms S. Classification of twins and neonatal morbidity. Obstet Gynecol. 1989;74:98-101.

Cite this article as: Gigi A, Alexander R, Radhamani K. Effects of twin pregnancy chorionic properties on fetal outcomes: a comparative study. Int J Reprod Contracept Obstet Gynecol 2020;9:3802-8. 